\section{EMBRYRIDDLE}

Aeronautical University

SCHOLARLY COMMONS
Journal of Aviation/Aerospace

Education \& Research

Volume 18

Number 3 JAAER Spring 2009

Article 16

Spring 2009

\title{
Using Peer and Team Performance Assessments as Learning Tools on Collaborative Student Projects
}

Timothy D. Ropp

Sergey Dubikovsky

Mary E. Johnson

mejohnson@purdue.edu

Follow this and additional works at: https://commons.erau.edu/jaaer

\section{Scholarly Commons Citation}

Ropp, T. D., Dubikovsky, S., \& Johnson, M. E. (2009). Using Peer and Team Performance Assessments as Learning Tools on Collaborative Student Projects. Journal of Aviation/Aerospace Education \& Research, 18(3). https://doi.org/10.15394/jaaer.2009.1433

This Article is brought to you for free and open access by the Journals at Scholarly Commons. It has been accepted for inclusion in Journal of Aviation/Aerospace Education \& Research by an authorized administrator of Scholarly Commons. For more information, please contact commons@erau.edu. 


\title{
USING PEER AND TEAM PERFORMANCE ASSESSMENTS AS LEARNING TOOLS ON COLLABORATIVE STUDENT PROJECTS
}

\author{
Timothy D. Ropp, Sergey Dubikovsky, Mary E. Johnson
}

\begin{abstract}
Leaving the team experience unevaluated during collaborative student projects leaves the educational benefit of student peer feedback unrealized. Performance feedback between student teams and among individual team members adds a valuable educational component during applied leaming projects. Faculty in the Aviation Technology program at Purdue University piloted the ușe of team and individual student peer evaluation tools as performance feedback and leaming mechanisms in two maintenance technology courses engaged in collaborative team projects. Use of peer performance reviews among the students during team-based projects resulted in willingness to engage in proactive problem solving and communication among students while individual scores in these areas increased.
\end{abstract}

Introduction

Many technology and engineering instructors utilize hands-on student team design projects for at least a portion of the classroom or laboratory experience. A targeted outcome for these immersive learning projects is student exposure to the dynamics of achieving technical deliverables within the context of a realistic tean environment. In addition to practicing baseline technical skill sets, students integrate key communication, negotiation, problem solving and planning skills, which are as important as technical skills for producing a deliverable in industry.

Although the use of team-centered leaming projects is quite common, students can miss an important dimension of learning if such projects are not debriefed and evaluated. In addition to the actual project experience, significant educational value and insight can be gained through detailed review and peer feedback annong student teams involved. This feedback can be facilitated by a structured team and peer review process.

\section{Method}

In the Spring and Fall semesters of 2007, students in two Purdue University aviation maintenance technology courses were introduced to the concept of being evaluated by their peers. The two courses each have specific technical content designed to build aircraft maintenance skills and knowledge. The students in these courses engaged not only in a team-based immersive learning approach on specific technical design projects, but were introduced to performance feedback tools requiring them to provide and receive constructive peer review of their participation and performance during team-based projects. During Spring, students in two technology courses began evaluating each other within their own course laboratory technical projects. In Fall of 2007, the two courses using the peer evaluations collaborated on selected projects requiring them to interact between the two courses, and then evaluate peer interaction performance between the two student teans.

While the classroom laboratory environment has limitations in replicating all aspects of a full scale working environment, the dynamics of working in teams with the added dimension of peer to peer evaluations resulted in student communication and problem-solving being more "proactive" in nahure. In both cases of student projects within a single course laboratory and in collaborative projects between two courses, student teams were observed looking for, identifying and resolving unforeseen problems during their technical design projects. Prior to implementation of the peer evaluation and feedback component, this forward-looking group effort was not 
previously noted by the instructors of these two courses.

One goal of the peer evaluation process was to lead students to view both internal and cross-disciplinary groups as internal customers, instead of just "coworkers" or a faceless outside entity. It is well known that key competencies such as team-based problem solving, communication and work load planning are as important as technical abilities to achieve deliverables in industry (Samuel, 2005) and employers demand a more comprehensive understanding of the engineering technology discipline and improved levels of communication skills from graduates of such programs (Shull, 2005; Bouckley, 2006; Ropp \& Stanley, 2006).

A project-based learning environment places demands of self-regulation on leamers, requiring the fluent application of interpersonal skills that may not have been previously required. Self-regulation is the self-directed use of disciplined work effort, communication and teamwork as described by Helle, Tynjala et.al., (2007) in a recent sndy of student self-regulation. This study evaluated similar scenarios in which students scoring low in self-regulation during project-based leaming were evaluated for indications of "friction" where this friction is seen as an incompatibility between student self-regulation and the demands posed by the learning environment. This is an especially important concept, as most jobs in industry today mandate selfregulation among individuals who must function on work teams chartered to be self-directed.

Courses used in student team collaboration projects

In an effort to replicate in the curriculum a selfdirected component of work teams, Purdue University faculty in the aviation technology curriculum developed and began practicing cross-disciplinary interaction between two senior level aviation technology courses. The students in these two courses interacted by identifying and solving technical problems requiring the skills and knowledge objectives in both of these courses. These courses were selected because of their similarity to interactions experienced in industry between aviation maintenance and technical support groups. The two senior courses selected were a senior aviation maintenance management course and a senior aviation maintenance manufacturing course as shown in Figure 1.

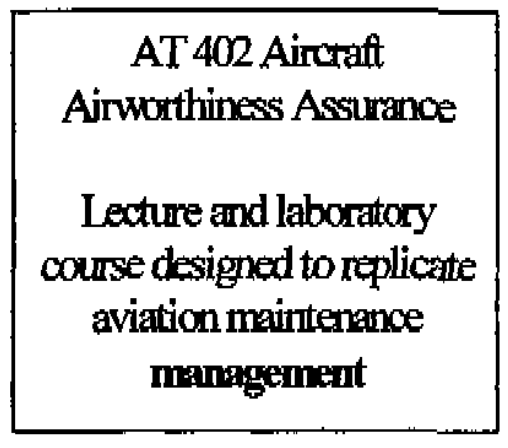

Figure 1. Two senior level courses participating in peer evaluation and feedback 
The first course is a senior level capstone aviation maintenance management course: AT 402 - Aircraft Airworthiness Assurance. This course simulates a maintenance operation utilizing the university's two large transport Boeing 737 and Boeing 727 aircraft. Senior maintenance technology students function as operations managers tasked with researching, planning and implementing a large aircraft production maintenance operation as an overall goal of the course. The first half of the course involves intense didactic review of leadership and performance management principles for managing technical teams and a technical review of the regulated aviation maintenance process. About 6 weeks into the semester, the AT 402 senior class then merges with a junior level class, AT 372 - Aircraft Maintenance Practices for the laboratory portions of both courses. The senior AT 402 students manage the junior AT 372 students, who take on the role of technical work crews accomplishing segments of aircraft in a large aircraft maintentance package specified by the instructor.

In addition to technical maintenance projects directly on the aircraft, the senior AT 402 "management team" is responsible for development of many major deliverables common to the industry such as technical writing for creation of job task cards, research and incorporation of safety management system components, use of process mapping in problem solving and process streamlining and orientation training delivery to the junior level student technical crews. The AT 402 team is simultaneously evaluated on the incorporation of key leadership competencies of communication, team building, planning, and problem solving into the technical deliverables of the laboratory maintenance crew activities. After each lab, the instructor evaluated and debriefed the sentior AT 402 team members on performance of team and communication criteria provided to the students and explained at the beginning of the semester. The students' peers then evaluated performance on the same criteria using peer feedback rating forms that contained the same team and communication criteria.

The second course selected was AT 408-Advanced Aircraft Manufacturing Processes. This senior level course has projects and outcome philosophies similar to those of AT 402, incorporating both technical and team work/leadership competency outcomes. In addition to just internal peer evaluations within one course laboratory, pairing AT $\mathbf{4 0 8}$ with AT 402 allowed additional important interactions similar to those found in the aviation industry between maintenance and support organizations, and which allowed additional peer to peer feedback outside of the student's own familiar course peer group.

Students in AT 408 have developed basic aircraft materials skills from prerequisite coursework within the curriculum. In this course, students integrate baseline technical skills with larger problem solving skills and processes involved in design and manufacture of more complex component parts, including structural joint design and aircraft components which play a critical role in flight safety in industry. The course is almost entirely projectbased allowing students to perform research and to design products to specific requirements. These projects are designed to help students better understand engineering fundamentals and technology applications in industry. Successful project completion also requites communication and planning skills as students acquire the new language of manufacturing, taking projects from planning to hands-on design and delivery. The students must follow all stages of the design process, including project cost assessment, establishing timelines and producing process sheet and work instructions.

Simulating an industrv working environment

During the AT 402 aircraft maintenance lab, student teams found aircraft part discrepancies requiring repairs beyond the normal scope of that laboratory's equipment or skill capabilities. More advanced manufacturing processes were requited to properly repair or rebuild the component. This is where the cross-disciplinary team-team interaction between the AT 402 and AT 408 courses came into play.

The student team in AT 402 presented and evaluated the identified discrepancies with the instructor to determine if they could be designated as "project level" requiring additional technical support. Repair design requirements for the part were researched by the AT 402 maintenance team and an Initial Project Request form for manufacturing support was initiated and delivered to the AT 408 advanced manufacturing laboratory. A brief project support meeting between the AT 402 and AT 408 student tearns was conducted to discuss and evaluate details of manufacture, cost and delivery estimates of the part with direct communication between the two teams. Subsequent follow-up meetings between AT 402 and AT 408 teams were held throughout the manufachuring process. Using a process similar to that in the aviation maintenance industry, a non-routine job card was created and placed on the AT 402 maintenance job board to track the part's routing status in the manufacturing lab and the estimated delivery.

This process, as illustrated in Figure 2, serves a dual purpose: to provide students with the educational experience of understanding the basics of work process flow 
and engineering, and to fulfill a legitimate technical support need of the laboratory aircraft.

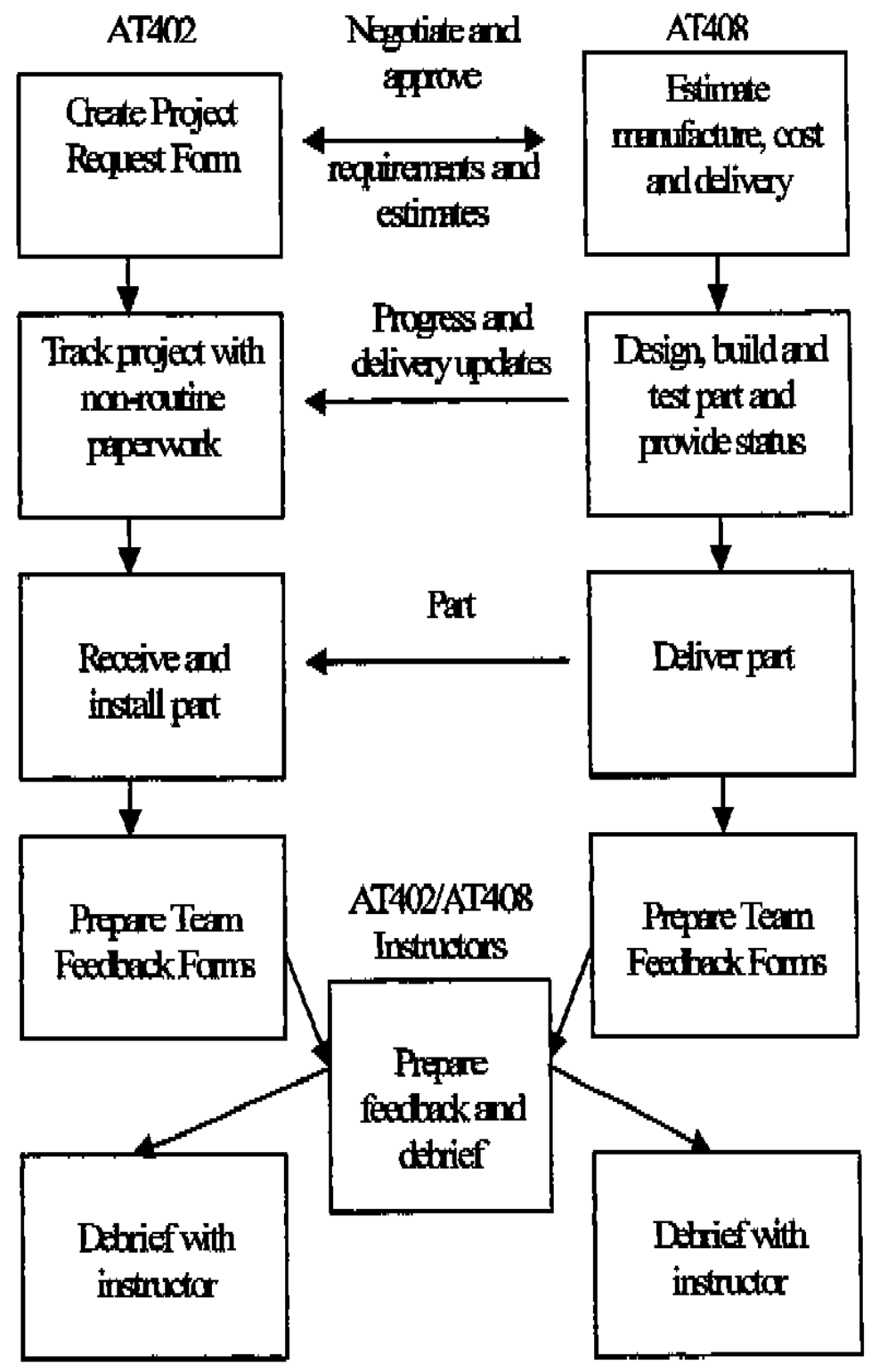

Figure 2. High level process diagram of team-team interaction 
The technical team interactions illustrated here emphasize what was perhaps the most important part of the exercise: leamers experienced the opportumity to work on multi-disciplinary teams achieving a common goal, while practicing the essential interpersonal skills and discipline required doing so effectively.

\section{Creating and Utilizing Team. Eyaluation Forms}

To provide a mechanism for discussion and reflection on the team project experience, two peer feedback forms were created, one evaluating the aggregate team experience between the two teams (Team Performance Feedback Form) and the other evaluating each individual's performance peer to peer within a team itself (Team Member Performance Feedback Form). Known behavioral performance criteria for high performing technical teams in the aviation industry which include benchmark behaviors in communication, workload management and team dynamics (Eiff, Ropp \& Mattson, 1997) were adapted to the AT 402 / AT 408 laboratory environment and their performance criteria incorporated into these forms, which are described below.

\section{Team Performance Feedback Form}

A Teann Performance Feedback Form was developed to encourage peer feedback on the aggregate team-team experience during the collaborative project. Each project team in AT 402 and AT 408 evaluated the other's performance from the perspective of each being an internal customer. AT $\mathbf{4 0 2}$ was considered the customer of a part manufactured by AT 408 . Conversely, AT 408 was viewed as a customer dependent on clear communication of requirements for a part requested by AT 402. Both "internal customers" had to be satisfied to provide effective maintenance operations and ultimately provide a safe, airworthy aircraft for the external customer - the flying public. This interaction between the classes emphasized the cross-disciplinary nature of industry project work and the recognition that technical skills must be supplemented with team skills to successfully solve problems.

To evaluate team to team performance, the form instructions read:

Please rate your experience interacting
with the AT408 / AT402 technical
group as an overall team during
project. Rate your experience in each
category by assigning a rating of $1-5$
for each, using the criteria scale
provided.

The form contains a series of questions with a 5-point Likert scale evaluating performance ranging from 1 meaning "did not meet expectations" to 5 meaning "exceeded expectations". These questions were developed to provide an opportunity for students to self-reflect on the key team performance competencies used during a detailed technical process. The student team decided as a group on a rating of the other team's overall performance in the following categories:

- Planning, preparation and documentation

- Verbal communication during meetings

- Participation in setting process direction and deadlines

- Incorporating safety considerations

In addition, the form contains two yes/no questions "Were agreed upon project deadlines met?" and "Did the final product meet design requirements?"

Team Member Peformance Feedback Form

A similar individual Team Member Perfortnance Feedback Form was also developed to provide peer to peer feedback from within each technical tearn. Each individual was asked to evaluate the performance of their peer team members individually. The form instructions read:

Please rate this individual's performance as a team member in today's lab. Rate your evaluation in each category by assigning a rating of 1 - 5 for each, using the criteria seale provided.

The form contains a series questions in the following four categories:

- Planning/preparation

- Communication

- Participation/contribution, and

- Incorporation of safety considerations.

A 5-point Likert scale was used, evaluating fellow team member's individual performance with a 5-point Likert scale evaluating peer performance ranging from 1 meaping "did not meet expectations" to 5 meaning "exceeded expectations". In addition, the form requeșted specific examples to support the ratings.

Initial Data Analysis

The data for the Fall 2007 Team Member Performance Feedback form was summarized for eight student teams as an "aggregate score" with possible scores ranging from 0 to 78 . Figure 3 is a scatterplot of the AT402 aggregate scores plotted versus time using Minitab software. To measure the extent of linear relationship between aggregate score and time, a Pearson correlation coefficient was calculated as 0.459 and indicates that the comrelation is 
positive. The Pearson correlation coefficient was significant at the $\alpha=0.05$ level. This graph indicates that aggregate scores increase as the semester noves forward. It is imporant to remember that correlation does not indicate causalion. More in-depth studies will be required to fully determine causation,

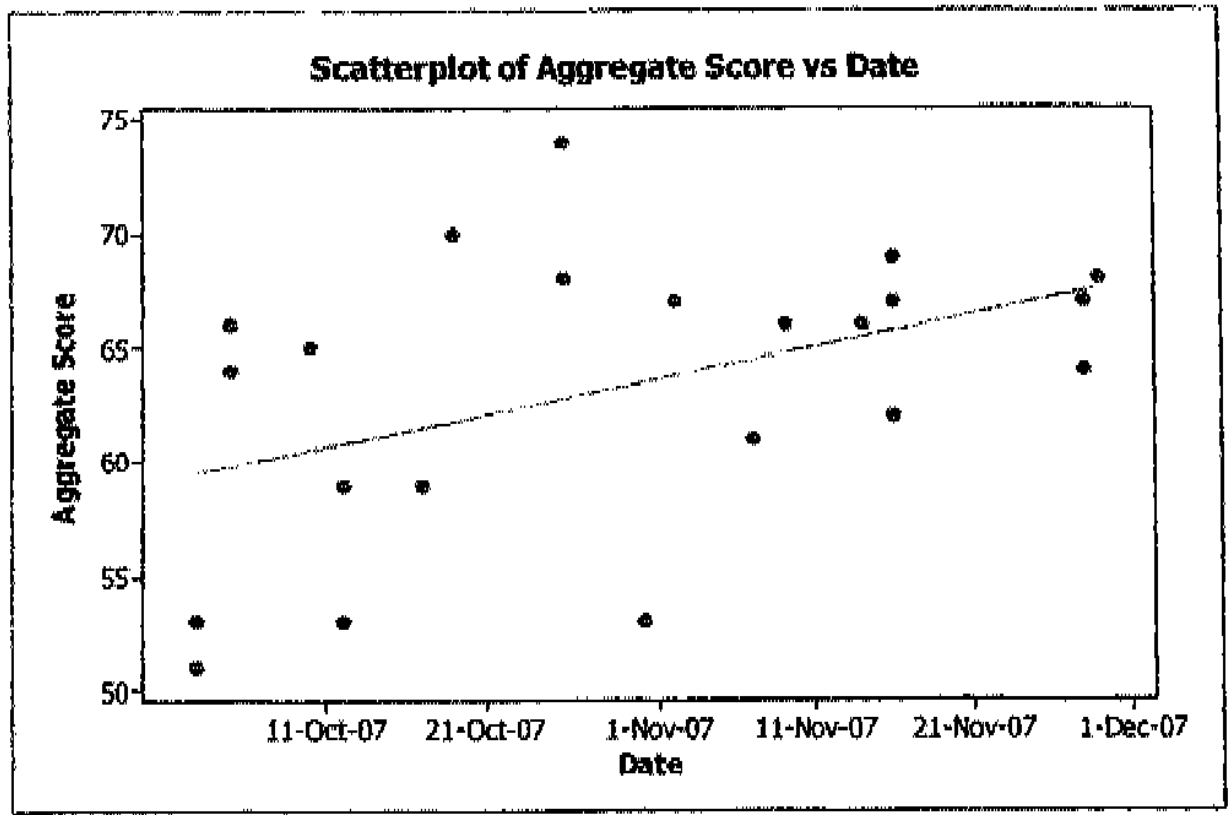

Figure 3. Scatterplot of Aggregate Score versus Date

The aggregate scores in Figure 3 may be further stratified by grouping the scores into three classes: 1) first score. 2) middle score, and 3 last score. There are three scores for tach of the eight students. Figure 4 shows the aggregate score data plotted in these groups using the Fitted Line Plot function in Minitab. 


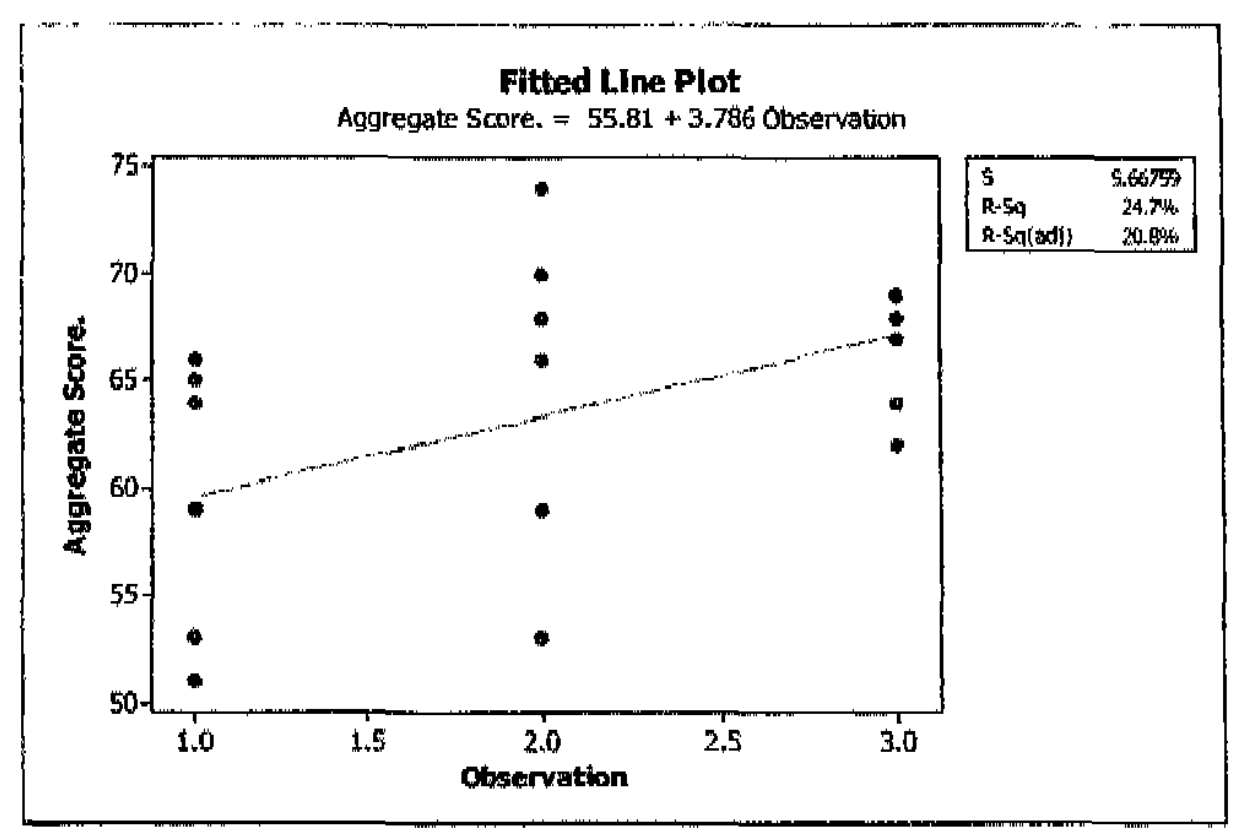

Figure 4. Fitted Line Plot of Aggregate Scores

The fitted line plot analysis in Figure 4 shows that the Agegregate Scors inay be modeled as equal to 55.81 t" 3.786 (Observation Number). This indicates that the score increases (improves) as the student team moves from initial score to final score. While the R-squared indicates that only $24.7 \%$ of the variation in the aggregate score is explained by the obstrvation number, the ANOVA for regression indicates a $p$-value of 0.022 which is significant at the $\alpha=0.05$ level. This means that we may conclude that the Observalion Number coefficient is not zero, and therefore there is a positive slope to the regression equation. The practical implication is that from this data. aggregate scores do improve over the course of the semester. Mors in-depth studies will be required to fully determine causation, and if this conclusion holds true for multiple semesters. The data for AT408 is not conclusive. A'7402 has used these forms for more than one year, while fall 2007 was the initial year for AT408. More coordination berween the course instructors is needed to ensure consistency of scoring by student teams.

\section{Results}

Early student performance and feedback on this experience was very positive, By allowing students to use the same team and communication criteria to evaluate each other, instructors noted gradtal improvement in studtent willingness to particinate to take on leadership or direction setting roles, and participate in group communication leading to problem solving. This was reflected in scoring improvements throughout the semester on individual 
performance scores. Practice and improvement of these "soft skills" were an unexpected net learning result for the student, self-discovered only after debriefing and evaluating the experience. Peer and team evaluation survey forms were used to emphasize the need for and perceived level of success in both technical and soft skills.

Conscious of the fact they would be evaluated on team performance skills as well as technical skills, students were noticeably more attentive to detail and engaged in the process, particularly in communication and seeking clarification on unclear concepts. This was noted by both instructors almost from the first day of class.

Instead of passive participation by some, nearly every student from both courses actively engaged in group discussion and problem solving efforts during projects. As the students began to get comfortable working with and being evaluated by each other at this level, they began to actively seek problems in a more self-directed manner. In AT $\mathbf{4 0 2}$ for example, whereas students would traditionally have come to the instructor for advice on a brokent part in need of repair or possible manufacture, students began performing their own research and needs assessment for the part, very often constructing a rough corrective plan of action before coming to the instructor. In many cases this plan of action was approved by the instructor, which built the confidence and assertiveness level of the students involved.

At the end of the semester, using course content and leatring evaluation forms where students were allowed to give anonymous, open ended feedback on the course, students reported satisfaction at having been required to exercise team skills in a more "realistic" work environment, even if they were unable to see a particular part through to manufacture given time or resource constraints. Knowing they would be evaluated by their own peers, and what they leamed about working on teams in this context was a very positive experience for the students, and students displayed overall planning, problem solving and communication performance more explicitly during laboratory work. Again, students expressed a perceived value using this collaborative, cross-disciplinary approach, in that it replicated "real-life" situations they anticipated facing in industry, while also serving a legitimate purpose for the aviation department in repair and preservation of laboratory aircraft.

\section{Future Directions}

The peer review forms and team process were piloted in the AT 402 and AT 408 course pairing this year and is continuing with planned expansion into other labotatory courses. As a means of continuous improvement, revisions and improvements to the forms have been established to better assess team behaviors as the process continues to evolve and becomes more refined. In 20082009, the AT 496 Research Design Proposal course and AT 497 Ressearch Applications course both plan to incorporate this form for use in the evaluation of team and individual performance on team design projects. These two courses are a series of a fall semester proposal course followed by a spring semester implementation course where the students work in teams to plan and conduct applied aviation research. Conclusion

The overall goal of using student team and peer performance feedback was to infuse team behaviors desired by industry throughout the senior level technical courses. Using team and individual peor feedback forms was a valuable educational component that would otherwise have been missed. Early results showed an increase in aggregate team and communication scores throughout the semester, however future work is needed to verify anecdotal observations and the early results reported here. Students experienced real-world problems of working on teams and reported related learning experiences in these areas as valuable takeaways from project experiences.t 
Timothy D. Ropp is Assistant Professor of Aviation Technology at Purdue University. He holds a BS in Aeronautical Technology and MS in Industrial Technology from Purdue University. He teaches AT 402, an upper division maintenance management capstone course using the school's B-737 and B-727 aircraft as hands-on laboratories. His research area is in immersive learning techniques for technology and engineerine curriculum and blending performance management competencies with technical skill sets and Safety Management Systems for aviation. He holds FAA Airframe and Powerplant and Private Pilot certificates, has worked in the airline industry in heavy maintenance, and consults internationally on safety management system education and implementation for aviation.

Sergey Dubikovsky is an Assistant Professor at Purdue University in the Aviation Technology department. He teaches AT 408, an aircraft materials and advanced manufachutug and design process course. His research focus is in immersive learning, team building, problem and project-based learning, international engineering education, globalization, Lean Six Sigma, threaded and specialized fasteners. He worked previously in industry as a design, product and project engineer. He has undergraduate and graduate degrees in Mechanical Engineering from South Ural State University (formerly Chelyabinsk Polytechnic Institute) in Russia.

Mary E. Johnson is an Associate Professor at Purdue University in the Aviation Technology department, where she teaches capstone proposal and design courses. She has worked in aerospace manufacturing and applied research. Her BS, MS and PhD are in Industrial Engineering from The University of Texas at Arlington. 


\section{References}

Bouckley, S. (2006). Filling workforce skill gaps. Manufacturing Engineering, 137(2),18-19.

Eiff, G.M., Ropp, T.D., \& Mattson, M. (1997). Proceedings from Soctety of Automotive Engineers Aerospace Airframe/Engine Maintenance \& Repair Conference. Using target performance indicators as a training and evaluation Tool. Vancouver, B.C. Canada. August 5 \& 6, 1997.

Helle, L., Tynjala, P., Olkinuora, E., Lonka, K. (2007). Ain't nothin' like the real thing: motivation and study processes on a work-based project course in information systems design. British Journal of Educational Psychology, 77(2), 397411.

Ropp, T.D. \& Stanley, D. (2006). Developing learning outcomes to fit industry metrics, Aviation Technician Education Council Journal (ATEC) 27(2), 37-39.

Samuel, L. (2005). Communication skills are keu (i.e. key) to career success. Water, Environment \& Technology, $17(2)$. 72.

Shull, P. J. (2005). Collaborative learning and peer assessment to enhance student performance. Journal of Engineering Technology, 22(1), 10-15. 